\title{
Shock rates in an unselected real world cohort of patients with medtronic protecta implantable cardioverter defibrillators
}

\author{
Rao $\mathrm{A}^{1 *}$, Barker $\mathrm{D}^{2}$, Ng Kam Chuen $\mathrm{MJ}^{3}$, Hughes $\mathrm{S}^{1}$, Cullen $\mathrm{D}^{1}$, Sharpe $\mathrm{A}^{4}$ and Wright $\mathrm{DJ}^{1}$ \\ ${ }^{1}$ Institute of Cardiovascular Medicine and Science, Liverpool Heart and Chest Hospital, Thomas Drive, Liverpool, L14 3PE, UK \\ ${ }^{2}$ University Hospitals of North Midlands NHS Trust, Newcastle Road, Stoke-on-Trent, ST4 6QG, UK \\ ${ }^{3}$ Nottingham University Hospitals NHS Trust, City Hospital Campus, Hucknall Road, Nottingham, NG5 1PB, UK \\ ${ }^{4}$ Medtronic, Inc., Minneapolis, Minnesota, USA
}

\begin{abstract}
Objective: To investigate rates of inappropriate shocks in patients with a Medtronic Protecta implantable cardioverter defibrillator device (Medtronic Inc., Minneapolis, MN, USA).

Methods: Consecutive patients implanted with Protecta defibrillators at a single centre between April 2010 and July 2012 were studied retrospectively.

Results: Follow-up data was available for 599 patients ( $84 \%$ male; age $64 \pm 14$ years, range 16-92; $49 \%$ secondary prevention indication; $42 \%$ cardiac resynchronisation therapy, $24 \%$ single chamber, and 34\% dual chamber defibrillator devices). Mean follow-up was $19 \pm 7$ months. 57 patients (9.5\%) received a shock: 8 patients(1.3\%) had inappropriate shocks; 50 patients $(8.3 \%)$ had appropriate shocks. Of the 10 inappropriate shocks, seven were for supraventricular tachycardia; one for T-wave oversensing; one due to lead displacement; and one occurred after an appropriate shock for ventricular tachycardia.
\end{abstract}

Conclusions: Our reported inappropriate shock rate over a 20-month follow-up period is lower than previously reported.

\section{Introduction}

Implantable cardioverter defibrillators (ICDs) reduce mortality in patients with a high risk of sudden cardiac death by treating life threatening ventricular arrhythmias [1]. The indications for ICDs are wide and expanding [2]. This therapy, however, is not without risk. As well as potential implant complications, patients are at risk of shocks, both appropriate and inappropriate. Shocks are painful, cause psychological distress and reduce quality of life [3]. In addition, an increased mortality risk has been associated with patients who receive shocks, although it remains unclear if this is related to the shock or if the shock is a reflection of more severe heart disease [4].

The percentage of ICD patients receiving unnecessary and inappropriate shocks has been reported to be up to $38 \%$ in historic cohorts [5]. This has led to an evolution in device algorithms as well as programming. In addition to device discrimination algorithms, non-committed shocks and anti-tachycardia pacing(ATP) [6] there is now increasing emphasis on strategic programming $[7,8]$ and delayed treatment to avoid unnecessary and inappropriate shocks $[4,9]$. Contemporary data suggest that the incidence of inappropriate shocks may be much lower $[10,11]$ than historically suggested. Real world data regarding the risks of shocks is important to counsel patients accurately at ICD implant; this data however, is currently lacking.

\section{Objective}

We aimed to evaluate the burden of shocks occurring in a realworld cohort of unselected patients implanted with Medtronic
Protecta $^{\mathrm{TM}}$ ICDs with SmartShock ${ }^{\mathrm{TM}}$ technology [12], using physiciandetermined programming parameters.

\section{Methods}

A retrospective, observational review of 600 consecutive patients implanted with a Medtronic Protecta ICD (single chamber (VRICD); dual chamber(DR-ICD); cardiac resynchronisation(CRT-D) from April 2010 until July 2012 was undertaken at The Liverpool Heart and Chest Hospital. This is a tertiary centre serving a population of 1.8 million and undertaking all ICD implants and follow up for the region.

\section{Study patients}

All patients were implanted for primary and secondary prevention as per the UK National Institute for Health and Care Excellence guidelines $[12,13]$. Patients with prior atrial fibrillation (AF) and prior slow ventricular tachycardia(VT) were included.

Correspondence to: Archana Rao, Cardiology Department, Institute of Cardiovascular Medicine and Science, Liverpool Heart and Chest Hospital, Liverpool, L14 5PE, UK. Tel: +44(0)151 600 1457, E-mail: archana.rao@lhch.nhs.uk

Key words: implantable cardioverter defibrillator shock, inappropriate shock, ventricular tachycardia, discriminators

Received: March 19, 2017; Accepted: April 20, 2017; Published: April 22, 2017 


\section{Device implantation, programming and follow up}

The chosen ICD system (ICD type; dual or single coil) was left to the discretion of the implanting physician, thus reflecting 'real world' practice. All ICD systems were implanted in the pectoral region, majority left-sided, under conscious sedation. Sensing, pacing thresholds and lead impedance were measured at the time of implant. Defibrillation threshold testing and ICD programming including detection, therapies, and use discriminators were at the discretion of the implanting physician. The Medtronic Protecta ICDs were the first ICD platform for the SmartShock ${ }^{\mathrm{TM}}$ technology, which comprises 6 exclusive discriminator algorithms(T wave discrimination, Lead Integrity Alert, Lead Noise Discriminator + Alert, PR Logic and Wavelet, Discrimination in the VF zone, Confirmation + ) aimed at discriminating true lethal arrhythmias from other arrhythmias and non-arrhythmic events [12].

Patient follow up was standardised as per the European Heart Rhythm Association (EHRA) recommendations [15] with a minimum of 3-6 monthly remote and at least 12 monthly ICD clinics follow ups. Follow up was complete in all patients except one, who relocated, and who has subsequently been excluded from our analysis. $60 \%$ of patients in this cohort were on routine 3-monthly remote monitoring via CareLink:

\section{Data collection}

Data from all implanted ICDs were collected through device interrogation. A review of both case notes and remote monitoring patient records from Medtronic CareLink and Discovery Link ${ }^{\mathrm{min}}$ systems was undertaken for every patient. Parameters included age, gender, implant date, initial or replacement device, primary or secondary indication, aetiology, left ventricular ejection fraction (LVEF), implant data, ICD programming and medication. The time and date, and electrograms, for all shocks and episodes detected as VT or ventricular fibrillation (VF) were reviewed independently by a cardiac physiologist and cardiologist. Data collection was completed on $13^{\text {th }}$ January 2013.

\section{Follow-up}

All patients were followed-up from the time of their ICD implantation until death, device explant or end-of-study. Information on cause of death was not available. All devices stored the date and time of episodes detected as VT/VF, detection programming at the time of episodes, and therapies delivered for each episode (e.g., number of shocks and number of ATP attempts). The majority of patient data including device printouts were scanned into the patient records allowing accurate recording of data. Stored electrograms were assessed by both cardiologist and physiologist in all cases of a delivered shock. An inappropriate shock was defined as a shock delivered for non-VT/ VF. Individual shocks in arrhythmia episodes were counted for the purposes of this study. VT storm was defined as the occurrence of 3 or more separate episodes of VT or VF episodes within a 24-hour period [16].

\section{Study outcomes and statistical analysis}

The study outcomes were total number of shocks, appropriate shocks, and inappropriate shocks. To standardise the data, shocks were analysed per 100 patient-years of follow-up. This included all shocks within episodes that are initially appropriately detected and treated, but where subsequent therapy was inappropriate, or vice- versa.

Programming (where available) was noted, with higher detection rates being defined as $>188 \mathrm{bpm}[8,9]$, and extended detection being defined as number of intervals to $\operatorname{detect}(\mathrm{NID})$ programmed to 30 out of 40 beats and above [8-10]. The time to event of appropriate and inappropriate shocks was analysed according to the method of Kaplan-Meier. Analyses were conducted with Stats Direct software version 2.7.9. The baseline criteria were compared using Chi squared test for categorical variables and T tests and Mann-Whitney tests for continuous variables. $\mathrm{P}$ values $<0.05$ were considered significant.

\section{Results}

\section{Patient demographics}

Complete follow-up data was available for 599 patients. Patients were followed-up for 19.4 \pm 7.1 months (range 7-32 months), resulting in a total of 967 patient-years of follow-up. The baseline characteristics of the patients are summarized in Table 1 . Patients were predominantly male(84\%), with mean age at implant of $64 \pm 14$ years(range 16-92 years). $33 \%$ of devices were implanted at generator change. $42 \%$ of patients received a CRT-D device, $24 \%$ a VR-ICD, and $34 \%$ a DRICD. 55\% received single-coil defibrillator leads. The device was implanted for secondary prevention in $49 \%$ of patients; $67 \%$ of patents had ischaemic aetiology; and $61 \%$ had severe left ventricular systolic dysfunction defined as $\mathrm{LVEF}<30 \%$. 142 patients (24\%) had a clear

Table 1. Patient demographics.

\begin{tabular}{|c|c|}
\hline Gender & \\
\hline Male, $n(\%)$ & $501(84 \%)$ \\
\hline \multicolumn{2}{|l|}{ Age (y), n (\%) } \\
\hline$<60$ & $179(30 \%)$ \\
\hline $60-69$ & $166(28 \%)$ \\
\hline$>70$ & $254(42 \%)$ \\
\hline \multicolumn{2}{|l|}{ ICD type, $\mathrm{n}(\%)$} \\
\hline CRT-D & $254(42 \%)$ \\
\hline DR & $202(34 \%)$ \\
\hline VR & $143(24 \%)$ \\
\hline \multicolumn{2}{|l|}{ ICD, n (\%) } \\
\hline Initial Implant & $403(67 \%)$ \\
\hline Replacement & $196(33 \%)$ \\
\hline \multicolumn{2}{|l|}{ Indication, $\mathbf{n}(\%)$} \\
\hline Primary prevention & $305(51 \%)$ \\
\hline Secondary prevention & $294(49 \%)$ \\
\hline \multicolumn{2}{|l|}{ Aetiology, n (\%) } \\
\hline Ischaemic cardiomyopathy & $404(67 \%)$ \\
\hline Dilated cardiomyopathy & $82(14 \%)$ \\
\hline Hypertrophic cardiomyopathy & $48(8 \%)$ \\
\hline $\begin{array}{l}\text { Arrhythmogenic right ventricular } \\
\text { cardiomyopathy }\end{array}$ & $17(3 \%)$ \\
\hline Other structural heart disease & $12(2 \%)$ \\
\hline Inherited channelopathy & $16(3 \%)$ \\
\hline Other indication & $20(3 \%)$ \\
\hline \multicolumn{2}{|l|}{ LVEF, n (\%) } \\
\hline$<35 \%$ & $368(61 \%)$ \\
\hline $35-50 \%$ & $162(27 \%)$ \\
\hline$>50 \%$ & $69(12 \%)$ \\
\hline \multicolumn{2}{|l|}{ Atrial fibrillation, $\mathrm{n}(\%)$} \\
\hline Definite documented prior AF & $42(24 \%)$ \\
\hline Unclear & $457(76 \%)$ \\
\hline \multicolumn{2}{|l|}{ Home monitoring, n (\%) } \\
\hline CareLink $^{\circledR}$ & $362(60 \%)$ \\
\hline \multicolumn{2}{|l|}{ Beta blocker therapy, n (\%) } \\
\hline Yes & $477(80 \%)$ \\
\hline No & $72(12 \%)$ \\
\hline Not documented & $50(8 \%)$ \\
\hline
\end{tabular}


documented history of AF prior to device implant. $80 \%$ of patients were taking beta-blockers at the time of implant. Forty-seven patients (7.8\%) died during the follow-up period and 2 had cardiac transplants.

\section{Shocks}

Of the 599 patients, and 57 patients $(9.5 \%)$ received at least one shock from their device(Table 2). Of the patients receiving shocks, 49 were solely appropriate, 7 solely inappropriate whilst 1 patient experienced both an appropriate and an inappropriate shock. This patient is therefore included in both categories. The mean time from implant to first shock was $9 \pm 6$ months (range 11 days to 2.5 years) (Figure 1). 13.9\% of secondary prevention patients and $5.6 \%$ of primary prevention patients received shocks. $50(8.3 \%)$ patients had appropriate shocks and received a total of 398 shocks. $8(1.3 \%)$ patients received 10 inappropriate shocks. Our total shock rate per 100-patient years was 42.2. Of these, 298 shocks occurred in patients with VT storm. The total appropriate shock rate was 41.2 per 100 -patient years and the total inappropriate shock rate was 1.03 per 100 -patient years. $13.3 \%$ of secondary prevention patients received appropriate shocks and 1.0\% received inappropriate shocks. $3.6 \%$ of primary prevention patients received an appropriate shock and $2 \%$ received an inappropriate shock.

Of the patients receiving shocks, $53 \%$ had a single shock, $29 \%$ had multiple shocks and 9 patients suffered a VT storm with between 6 and 81 shocks, which were all appropriate.

\section{Inappropriate shocks}

$1.3 \%$ of our cohort had inappropriate shocks at 20 months' follow up. 8 patients suffered 10 inappropriate shocks (Table 3), resulting in an inappropriate shock rate of 1.03 per 100 patient-years). Six of the 8 patients with inappropriate shocks were taking beta-blockers (75\%). The patients suffering inappropriate shocks had VT/ fast VT zones from 167-200 bpm and VF zones from 200-240 bpm. Five of the $10(50 \%)$ inappropriate shocks were for AF/atrial flutter. One episode occurred in redetection after an appropriate shock for VT and one episode resulted in shock therapy due to high rate timeout only; wavelet was appropriately withholding therapy. High rate time out is nominally programmed OFF, however was left on by omission for this particular patient. Of the 5 patients who had an inappropriate shock for AF, $4(80 \%)$ had previously documented AF.

One patient suffered 2 shocks for atrio-ventricular re-entry tachycardia (AVRT) whilst taking beta-blocker at the time; the SVT rate was $240 \mathrm{bpm}$, thus outside the programmed discrimination zone. He later had successful AVRT ablation. One shock was delivered for $\mathrm{T}$-wave oversensing in a patient with a very small $\mathrm{R}$ wave $(1.1 \mathrm{mV})$ and another patient had 2 shocks due to right ventricular ICD lead displacement into the right atrium.

\section{VT storms}

9 patients suffered VT storms, all with appropriate shocks (Table 4). The range of shocks was 6-81, with a total number of 298 shocks. $80 \%$

Table 2. Shock data

\begin{tabular}{|c|c|c|c|c|c|}
\hline & $\begin{array}{c}\text { Number of } \\
\text { patients }\end{array}$ & $\begin{array}{c}\text { Patient-years } \\
\text { of follow-up }\end{array}$ & $\begin{array}{c}\text { Number of } \\
\text { patients with } \\
\text { shocks }\end{array}$ & $\begin{array}{c}\text { Number of } \\
\text { shocks }\end{array}$ & $\begin{array}{c}\text { Shock rate } \\
\text { per 100 } \\
\text { patient-years }\end{array}$ \\
\hline All patients & 599 & 967 & 57 & 408 & 42.2 \\
\hline $\begin{array}{c}\text { Secondary } \\
\text { prevention }\end{array}$ & 294 & 471 & 40 & 296 & 62.8 \\
\hline $\begin{array}{c}\text { Primary } \\
\text { prevention }\end{array}$ & 305 & 496 & 17 & 112 & 22.6 \\
\hline $\begin{array}{c}\text { New implants } \\
\text { Generator } \\
\text { changes }\end{array}$ & 403 & 655 & 37 & 281 & 42.9 \\
\hline
\end{tabular}

Table 3. Cause of inappropriate shocks.

\begin{tabular}{|c|c|c|c|c|c|c|}
\hline Patient & $\begin{array}{c}\text { Number } \\
\text { of shocks }\end{array}$ & Cause & Comment & $\begin{array}{c}\text { Beta } \\
\text { blockers }\end{array}$ & Treatment & $\begin{array}{c}\text { History } \\
\text { of AF }\end{array}$ \\
\hline 1 & 1 & $\mathrm{AF}$ & & Yes & & Yes \\
\hline 2 & 2 & SVT & Rate $240 \mathrm{bpm}$ & Yes & $\begin{array}{c}\text { AVRT } \\
\text { ablation }\end{array}$ & No \\
\hline 3 & 2 & $\begin{array}{c}\text { Lead } \\
\text { displacement }\end{array}$ & & $\begin{array}{c}\text { No - } \\
\text { COPD }\end{array}$ & $\begin{array}{c}\text { Lead } \\
\text { repositioned }\end{array}$ & Yes \\
\hline 4 & 1 & $\mathrm{AF}$ & Rate $188-214$ bpm & Yes & & No \\
\hline 5 & 1 & Atrial Flutter & & No-asthma & & Yes \\
\hline 6 & 1 & $\mathrm{AF}$ & $\begin{array}{c}\text { in redetection } \\
\text { following an } \\
\text { appropriate shock }\end{array}$ & Yes & & No \\
\hline 7 & 1 & $\begin{array}{c}\text { T wave over- } \\
\text { sensing }\end{array}$ & $\mathrm{R}$ wave $1.1 \mathrm{mV}$ & Yes & $\begin{array}{c}\text { Device } \\
\text { and lead } \\
\text { explanted }\end{array}$ & Yes \\
\hline 8 & 1 & $\mathrm{AF}$ & $\begin{array}{l}\text { high rate timeout } \\
\text { on (would } \\
\text { have withheld } \\
\text { otherwise) }\end{array}$ & Yes & $\begin{array}{l}\text { High rate } \\
\text { timeout } \\
\text { turned off }\end{array}$ & Yes \\
\hline
\end{tabular}

Table 4. VT storms

\begin{tabular}{|c|c|c|c|c|}
\hline Patient & $\begin{array}{c}\text { Number of } \\
\text { shocks }\end{array}$ & Cause & Beta blockers & Treatment \\
\hline 1 & 35 & FVT \& VF & Yes & Amiodarone \\
\hline 2 & 46 & intractable VT & Yes & Amiodarone, later died \\
\hline 3 & 81 & VT storm & Yes & VT ablation \\
\hline 4 & 32 & VT storm & Yes & $\begin{array}{c}\text { Amiodarone and beta } \\
\text { blockers }\end{array}$ \\
\hline 5 & 24 & VT storm & No, amiodarone & VT ablation \\
\hline 6 & 6 & VT storm & Yes & $\begin{array}{c}\text { Both bisoprolol and } \\
\text { sotalol }\end{array}$ \\
\hline 7 & 10 & VT storm & $\begin{array}{c}\text { Yes, and } \\
\text { amiodarone }\end{array}$ & VT ablation \\
\hline 8 & 26 & $\begin{array}{c}\text { Torsades de } \\
\text { points }\end{array}$ & Yes & Amiodarone, later died \\
\hline 9 & 38 & VT storm & Yes & \\
\hline & & & & \\
\hline
\end{tabular}

occurred in secondary prevention patients. Three patients with storms went on to have VT ablation and 2 patients died during the follow-up period. 9 of the 10 patients were on beta-blocker therapy at the time of the VT storm, including one patient subsequently commenced on both bisoprolol and sotalol. 70\% were on amiodarone. 2 had CRT-D, 5 DRICD, and 2 VR-ICD in situ. 3 of the 9 patients were programmed with a NID of 30 out of 40 beats, the rest were nominal at 18 out of 24.7 of the 9 patients had VT detection limit programmed to $<188 \mathrm{bpm}$ and the rest has detection programmed to $>188 \mathrm{bpm}$.

\section{Generator changes}

196(33\%) of the patients included in the study underwent generator change. $21(10.7 \%$ ) patients suffered 136 shocks (shock rate 40.7 per 100 patient-years). Four of generator change patients had 5 inappropriate shocks. The appropriate shock rate in generator change patients was 43.6 per 100 patient-years and the inappropriate shock rate 1.92 per 100 patient-years.

\section{Atrial fibrillation}

Twenty-four percent of patients had previously documented AF. $5(50 \%)$ of the 10 inappropriate shocks were due to AF or atrial flutter. Of the 8 patients suffering inappropriate shocks 5(62.5\%) were for AF/ atrial flutter. $4(80 \%)$ of the 5 patients had a previous history of AF. All but one of these patients were on beta-blockers, for the remaining patient, beta blockers were contraindicated due to asthma. 137 patients with a documented history of paroxysmal or persistent AF had no inappropriate shocks. 


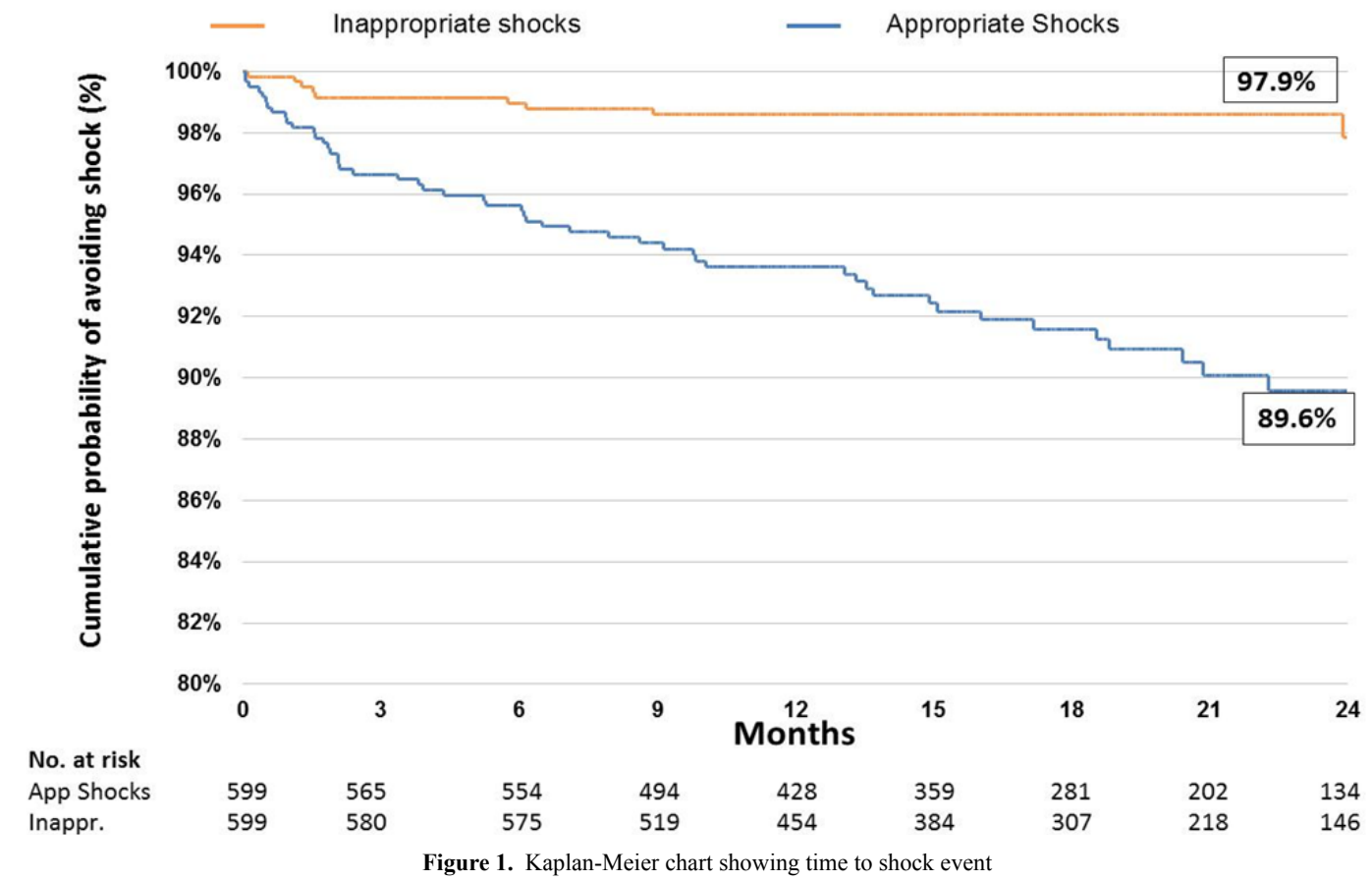

\section{Programming}

Programming was at implanter discretion. 59\% of patients had 3 zones programmed; $34 \%$ two zones programmed and $7 \%$ had a single zone only. VT zones were programmed from 120-182 bpm, FVT zones between154-210 bpm and VF zones between188-260 bpm. Detailed programming data was available for 431 patients. Of these, 257(60\%) had high rate detection i.e., $\geq 188 \mathrm{bpm}$ programmed. $23(8.9 \%)$ of these 257 patients experienced shocks of which 2 experienced VT storm and 7(2.7\%) experienced inappropriate shocks. $174(40 \%)$ of the 431patients had detection programmed to treat slower tachycardias i.e., $<188 \mathrm{bpm} .35(20 \%)$ of these 174 patients experienced shocks and 7(4\%) experienced a VT storm and 1 patient had inappropriate shock.

$63 \%$ of patients had VF NID programmed to $18 / 24$ and $38 \%$ delayed detection, mainly 30 out of 40 beats. None were programmed to NID 12 out of 16 beats. SVT discriminators were enabled, and ATP was programmed as the initial therapy, in $100 \%$ of the patients. ATP during or before charge in the VF zone was enabled on all patients.

\section{Discussion}

Research across early generations of ICDs indicate that the occurrence of shock, and particularly five or more shocks, is associated with decreased quality of life, causing significant anxiety for both ICD recipients and their relatives [3]. Shocks, both appropriate and inappropriate, are also associated with significant morbidity and mortality [4]. Shock reduction in ICD recipients has thus been a priority both for clinicians, patients and the industry, but progress in this area has been impeded due to fear of avoidable mortality and syncope. There is now good evidence to suggest that individualised programming utilising higher detection rates, prolonged detection and several attempts of ATP before shock delivery is safe and will reduce shock incidence and improve mortality as compared with uniform shock-only programming used in previous trials $[7,8]$.

More recently, 2 large randomised trials reported significant reduction in "combined therapy" from $\operatorname{ICD}$ (shocks and ATP) as a composite end- point with the primary focus on device programming and delayed arrhythmia detection strategies [4,9]. Analysis of the Sudden Cardiac Death in Heart Failure Trial (SCD-HeFT) data [5] showed findings similar to those of the MADIT-II study. In the SCDHeFT study, 33\% of patients received an ICD shock, and among those patients, the most common cause of death was progressive heart failure. Patients receiving an appropriate shock had a 5-fold increase in risk of death, whereas patients receiving an inappropriate shock had a 2-fold increase in risk of death. Pooled data from the Pacing Fast Ventricular Tachycardia Reduces Shock Therapies (PainFREE Rx) trial, the PainfREE Rx II trial, the Comparison of Empiric to Physician-Tailored Programming of Implantable Cardioverter-Defibrillators(EMPIRIC) trial, and the Primary Prevention Parameters Evaluation(PREPARE) study confirmed poorer survival in patients shocked for ventricular arrhythmias compared to patients treated with anti-tachycardia pacing only [17].

We therefore believe that actual shock rate is more important to patients and it is important for caregivers to be aware of the likely shock rate when considering the risks and benefits of ICD implantation. The Computer modelling of the SmartShock ${ }^{\mathrm{TM}}$ technology [18] suggested a very low rate of inappropriate shocks was safely achievable with nominal settings. We had a large cohort of patients with these devices implanted in unselected patients and aimed to assess the shock rate in clinical practice. Our study was performed to evaluate the shock rate both appropriate and inappropriate in all patients implanted with Medtronic Protecta Devices.

Our results indicate that the overall shock rate was $9.5 \%$ and inappropriate shock rate was $1.3 \%$ at 20 months follow up. The results confirm in a large real world population, the low inappropriate shock rates described in PainFree SST study [10]. Our study differs from both Advance III [9] and MADIT-RIT [4] in that it represents data from an unselected "real world" population and we report "shock data" and not therapy data (i.e., composite shock +ATP). We therefore report on total number of shocks including VT storms experienced. We included all patients implanted with a Medtronic Protecta ICD within 
the study time frame, of whom $49 \%$ were implanted for secondary prevention, 24\% had $\mathrm{AF}$ and $33 \%$ underwent generator changes. We also included VR-ICD, DR-ICD and CRT-D with operator-initiated programming tailored to individual patient needs. Our population were predominantly male $(84 \%)$ in keeping with most ICD studies $[2,5]$, with diverse aetiologies accounting for the wide age range and relatively young age of our generator change population. $57(9.5 \%)$ of patients received a shock; of these 50 received appropriate shocks, 8 received inappropriate shocks (1 patient received both an inappropriate and appropriate shock). The total number of shocks received was 408 of which 10 were inappropriate.

The burden of shocks in our cohort was 42.2 per 100 patient years. As expected, the shocks rate was significantly higher in the secondary prevention population (62.8 per 100 patient years) compared to the primary prevention population (22.6 per 100 patient years). This figure appears to be much higher than those experienced in the ADVANCE III study [9], a randomised trial of 1902 patients undergoing first ICD implant between 2008-2010. We propose that this is because our shock rate per 100 patient years is the actual number of shocks as experienced by the patient, as opposed to shock episodes. In ADVANCE III, a shock episode was defined as an ICD detection during which 1 or more shocks occurred and episodes caused by the same type or arrhythmia beginning within 5 minutes of another episode were not counted or reanalysed. Consequently, limited information is available from ADVANCE III or MADIT RIT [4] on VT storms. Limited information is available from randomised controlled trials on VT storms despite the fact that this has a very profound impact on patients' outcomes. In our cohort, 9(1.5\%) patients experienced VT storms resulting in a total of 298 shocks (range 6-81). The mortality in this group was $22 \%$. $7(80 \%)$ of the 9 patients had secondary prevention devices in situ. We observed no storms of inappropriate shocks in this study and had no lead fractures in the study cohort. In the MADIT RIT trial [4] (primary prevention indication for defibrillator implantation only), 514 patients were randomised to conventional programming with detection rates of $170 \mathrm{bpm}$ and 986 to long-detection or high rate programming. Interestingly there was no significant difference in the proportion of patients receiving appropriate shocks in the conventional versus high rate ( $\mathrm{p}=0.86)$ or delayed therapy arms $(\mathrm{p}=0.25)$ although the number of patients receiving inappropriate shocks was reduced $(6 \%$ versus $3 \% \mathrm{p}=0.03)$.

\section{Inappropriate therapy}

$11.5 \%$ of the MADIT-II patients (primary prevention with VRICDs and DR-ICDs) had 1 or more inappropriate shocks with a $13 \%$ likelihood at 2 years of having an inappropriate shock [1]. AF or atrial flutter were the most common cause for inappropriate shock, followed by SVT, with inappropriate sensing being the least common mechanism [1]. Our finding of $1.3 \%$ inappropriate shocks at 20 months' followup compares very favourably especially as $24 \%$ of our cohort had AF. Interestingly, 5 out of $9(56 \%)$ of these inappropriate shocks were for AF confirming that this remains a problem in the real world.

A third of our cohort consisted of generator changes (196/599) and the mean age of these patients was $65 \pm 13$ years, which was not significantly higher than the age of patients with virgin implants. Furthermore, appropriate shock rates were comparable to that of the rest of cohort with appropriate shocks rates of 43.6 per 100 patient years versus 41.2 for virgin implant suggesting that any decision to avoid box changes needs to be made with caution. No data is available on shock history of generator replacement patients or if they still satisfied current criteria for ICD implantation.
The results indicate that the incidence of inappropriate therapy in this platform of devices is very low at $1.3 \%$ at 20 months. This is comparable to the PainFree SST study which showed an inappropriate shock rate of $1.5 \%$ at 12 months for DR-ICD and CRT-D patients and $2.5 \%$ for VR-ICD patients [10]. Another recent study looking at "real world" data from the Ontario ICD database (one third primary prevention and two third secondary prevention indication) using similar physician-assigned ICD therapy with ATP reported that $7.3 \%$ of patients experienced an appropriate shock after 1 year of follow up [19].

\section{Clinical implications}

The low rate of inappropriate shocks is a welcome finding, applicable to secondary prevention cohorts in the "real world". Our study predates ADVANCE III and MADIT RIT [4], which have largely impacted contemporary device programming to avoid inappropriate shocks. Our study was not designed to assess the effect of programming decisions and the low rate of inappropriate shocks is likely attributable to the effectiveness of the SmartShock ${ }^{\mathrm{TM}}$ device algorithms at correctly identifying rhythms which do not require shock. The overall lower rate of appropriate shocks and mortality at 20 months compared to historic studies may be due to increased beta-blocker use, different risk factors of the populations being implanted with devices and improved discrimination algorithms. Furthermore, the Liverpool Heart and Chest Hospital is a large volume tertiary centre with longstanding expertise in ICD management, such that optimal individualised ICD programming is likely to have taken place at the implanter's discretion.

\section{Limitations}

The main limitations of this study are inherent to the observational and retrospective nature of the study design. All patients in the study received devices produced by a single manufacturer thus our results may only apply to patients with ICDs from this manufacturer. Our follow-up was for 20 months with no data collected for longer-term shock rates. We also acknowledge that programming was performed at the discretion of the physician and therefore subject to selection bias, but we believe that this adds credence to the "real world" nature of the study and makes the low inappropriate shock rates even more reassuring.

\section{Conclusions}

In this cohort of patients receiving a Medtronic Protecta ICD with SmartShock ${ }^{\mathrm{TM}}$ technology, appropriate shocks were required in $13.9 \%$ of secondary prevention and $3.9 \%$ of primary prevention patients, with inappropriate shocks occurring in $1.3 \%$ of patients over a 20 month mean follow-up period. This data may be useful for counselling patients who require ICD therapy and confirms a lower rate of inappropriate shocks than previously reported.

\section{Financial disclosure}

Archana Rao, Diane Barker and Jay Wright have educational contracts with Medtronic and have received honoraria from Medtronic and Boston Scientific Corporation. MJ Ng Kam Chuen has received honoraria from Medtronic. Angela Sharpe is an employee of Medtronic.

\section{References}

1. Moss AJ, Zareba W, Hall WJ, Klein H, Wilber DJ, et al. (2002) Prophylactic implantation of a defibrillator in patients with myocardial infarction and reduced ejection fraction. $N$ Engl J Med 346: 877-883. [Crossref] 
2. Brignole M, Auricchio A, Baron-Esquivias G, Bordachar P, Boriani G, et al. (2013) 2013 ESC Guidelines on cardiac pacing and cardiac Resynchronization therapy:the Task Force on cardiac pacing and resynchronization therapy of the European Society of Cardiology (ESC). Developed in collaboration with the European Heart Rhythm Association (EHRA). Eur Heart J 34: 2281-329. [Crossref]

3. Schron EB, Exner DV, Yao Q, et al. (2002) Quality of Life in the Antiarrhythmic Versus Implantable Defibrillators Trial. Impact of Therapy and Influence of Adverse Symptoms and Defibrillator Shocks. Circulation 105: 589-594.

4. Moss AJ, Schuger C, Beck CA, Brown MW, Cannom DS, et al. (2012) Reduction in inappropriate therapy and mortality through ICD programming. $N$ Engl $J$ Med 367: 2275-2283. [Crossref]

5. Saxon LA, Bristow MR, Boehmer J, Krueger S, Kass DA, et al. (2006) Predictors of Sudden Cardiac Death and Appropriate Shock in the Comparison of Medical Therapy, Pacing, and Defibrillation in Heart Failure (COMPANION) Trial. Circulation 114: 2766-2772. [Crossref]

6. Wathen MS, DeGroot PJ, Sweeney MO, Stark AJ, Otterness MF, et al. (2004) Prospective Randomized Multicenter Trial of Empirical Antitachycardia Pacing Versus Shocks for Spontaneous Rapid Ventricular Tachycardia in Patients with Implantable Cardioverter-Defibrillators. Pacing Fast Ventricular Tachycardia Reduces Shock Therapies (PainFREE Rx II) Trial Results. Circulation 110: 2591-2596. [Crossref]

7. Wilkoff BL, Ousdigian KT, Sterns LD, Wang ZJ, Wilson RD, et al. (2006) A Comparison of Empiric to Physician-Tailored Programming of Implantable CardioverterDefibrillators Results from the Prospective Randomized Multicenter EMPIRIC Trial. $J$ Am Coll Cardiol 48: 330-339. [Crossref]

8. Wilkoff BL, Williamson BD, Stern RS, Moore SL, Lu F, et al. (2008) Strategic Programming of Detection and Therapy Parameters in Implantable CardioverterDefibrillators Reduce Shocks in Primary Prevention Patients: Results from the PREPARE (Primary Prevention Parameters Evaluation) Study. J Am Coll Cardiol 52: 541-550. [Crossref]

9. Gasparini M, Proclemer A, Klersey C, Kloppe A, Lunati M, et al. (2013) Effect of long-detection interval vs standard-detection interval for implantable cardioverterdefibrillators on antitachycardia pacing and shock delivery. The ADVANCE III Randomized Clinical Trial. JAMA 309: 1903-1911. [Crossref]
10. Auricchio A, Schloss EJ, Kurita T, Meijer A, Gerritse B, et al. (2015) Low inappropriate shock rates in patients with single- and dual/tripe-chamber implantable cardioverterdefibrillators using a novel suite of detection algorithms: PainFree SST trial primary results. Heart Rhythm 12: 926-936. [Crossref]

11. Weeke P, Johansen JB, Jørgensen OD, Nielsen JC, Møller M, et al. (2013) Mortality and appropriate and inappropriate therapy in patients with ischaemic heart disease and implanted cardioverter-defibrillators for primary prevention: data from the Danish ICD Register. Europace 15: 1150-1157. [Crossref]

12. Medtronic ${ }^{\mathrm{TM}}$ Protecta $^{\mathrm{TM}}$ XT Manual http://manuals.medtronic.com/manuals/main/ region.

13. NICE Technology appraisal guidance 95: Implantable cardioverter defibrillators for arrhythmias, 2006

14. NICE Technology appraisal guidance 120: Cardiac resynchronisation therapy for the treatment of heart failure, 2007.

15. Daubert JC, Saxon L, Adamson PB, Auricchio A, Berger RD, et al. (2012) 2012 EHRA/ HRS expert consensus statement on cardiac resynchronization therapy in heart failure: implant and follow-up recommendations and management. Heart Rhythm 9: 15241576. [Crossref]

16. Gasparini M. Lunati M, Landolina M, et al. (2008) Electrical storm in patients with biventricular implantable cardioverter defibrillator; incidence, predictors, and prognostic implications. Am Heart $J$ 156: 847-854.

17. Sweeney MO, Sherfesee L, DeGroot PJ, Wathen MS, Wilkoff BL (2010) Differences in the Effects of Electrical Therapy Type for Ventricular Arrhythmias on Mortality in Implantable Cardioverter-Defibrillator Patients. Heart Rhythm 7: 353-360. [Crossref]

18. Volosin KJ, Exner DV, Wathen MS, Sherfesee L, Scinicariello A, et al. (2010) Combining Shock Reduction Strategies to Enhance ICD Therapy: A Role for Computer Modeling. J Cardiovas Electrophysiolol 22: 280-289. [Crossref]

19. Macfadden DR, Crystal E, Krahn AD, Mangat I, Healey JS, et al. (2012) Sex differences in implantable cardioverter-defibrillator outcomes: findings from a prospective defibrillator database. Ann Intern Med 156: 195-203. [Crossref]

Copyright: (C2017 Rao A. This is an open-access article distributed under the terms of the Creative Commons Attribution License, which permits unrestricted use, distribution, and reproduction in any medium, provided the original author and source are credited. 